\title{
Estimation of annual external exposure and internal exposure dose rate for gamma ray from the Natural Radionuclides in cultivated, uncultivated and phosphate soil samples
}

\author{
S. Harb \\ Physics Department, Faculty of science, South Valley university, 53832 Qena, Egypt \\ shaban.harb@sci.svu.edu.eg
}

\begin{abstract}
The aim of this work, to estimate the External exposure, ingestion Exposure and inhalation exposure dose rate from gamma ray released from Natural Radionuclides in cultivated, uncultivated and phosphate soil samples in the area surrounding EL-Naser Factory for phosphate in El-Mahamid, Idfu, Aswan, Upper Egyp by using modeling, this model studied the exposure gamma radiation from different natural radionuclides ${ }^{226} R a$, and ${ }^{228} \mathrm{Ra}$, in samples, and also using conversion factors for all radionuclides for different ages according to ICRP 90. The activity concentration ranged for ${ }^{226} R a$ was $13.2 \pm 0.5-34.3 \pm 1.3$ and for ${ }^{228} R a$ was $12.2 \pm 0.5$ $24.4 \pm 0.9$, for ${ }^{226} \mathrm{Ra}$ was $5.5 \pm 0.3-41.8 \pm 1.5$ and for ${ }^{228} \mathrm{Ra}$ was $4.0 \pm 0.2-22.0 \pm 0.8$ and for ${ }^{226} \mathrm{Ra} 20.7 \pm 0.7$ $590.9 \pm 19.2$ and for ${ }^{228} \mathrm{Ra}$ was $125.1 \pm 42-277.4 \pm 1.5$ for cultivated, uncultivated and phosphate soil samples respectively.
\end{abstract}

\section{Introduction}

Natural background radiation is the combined radiation field produced by the primordial and cosmogenic radioactive materials that are around us plus cosmic radiation from space. Everyone is exposed to this background radiation throughout their lives, at levels that depend on the ambient concentration of those radioactive materials and the altitude at which we live. This background radiation is the major source of radiation exposure to humans. Natural background dose rates are frequently used as a standard of comparison for doses from various man-made sources of radiation and also from the production, testing and use of nuclear weapons (1).

Surface soil can become contaminated with radionuclides through: many different mechanisms such as airborne deposition spills and leaching from contaminated material stored above ground. Current activities associated with the clean-up of contaminated weapons production and storage facilities might result in additional soil contamination as well as in the discovery of past contamination. Even after clean-up of known contaminated land, some residual contamination will remain. The calculated doses are deliberately designed to conservatively represent the maximum dose to any individual. Thus, these doses are inappropriate for use in calculating population exposures or to estimate health effects. The calculation of doses to actual individuals requires the use of site-specific and individual specific parameters in the formulas used for the calculations.(2)

Only surface soil contamination refers only to depths comprising the below layer. i.e., down to a depth of about $30 \mathrm{~cm}$. The guidance here in is not intended to be used for evaluating the implications of an on going contamination episode such as a continuing airborne deposition. All other important dose pathways are considered including external radiation exposure, ingestion of contaminated foodstuffs, direct and indirect ingestion of soil by humans and animals, and both indoor and outdoor inhalation of resuspended material.

Exposures to radionuclides may be internal or external, and effects are caused by energetic particles or rays released as part of the decay of atoms. Decay energies of particles or rays emitted by each radionuclide must be accounted for. The internal and external doses from all radionuclides present must be summed to arrive at the appropriate exposure dose for a given organism. In addition, a number of radionuclides have daughter products that must also be included in the exposure calculations. Internal exposures result from ingestion of contaminated food, soil, or water or inhalation of contaminated soil or dust. External exposures result from direct exposure to radiation from the soil and may occur either above or below ground. In all cases, the radiation source must be known in terms of the quantity of each specific radionuclide $\left(\mathrm{Bq} \mathrm{kg}^{-1}\right)$ (3)

\subsection{Sample preparation}

\section{Experimental and sampling}

Samples were collected from different places at the area surrounding EL-Naser Factory for phosphate in El-Mahamid, Idfu, Aswan, Upper Egypt as shown in the figure (1). These samples are cultivated $\left(25^{\circ}\right.$ $\left.8^{\prime} 28.07 " \mathrm{~N}-32^{\circ} 46^{\prime} 4.40 " \mathrm{E}\right)$, uncultivated soils $\left(25^{\circ} 8^{\prime} 23.63{ }^{\prime \prime} \mathrm{N}-32^{\circ} 46^{\prime} 29.51 " \mathrm{E}\right)$ and phosphate rock samples $\left(25^{\circ}\right.$ $\left.7 ' 26.50 " \mathrm{~N}-25^{\circ} 7 ' 26.50 " \mathrm{~N}\right)$. from inside factory borders. These samples were collected by using the global 
positioning system "GPS" which determines the Longitude and Latitude of samples places. All samples prepared and measured in Environmental Radioactivity measurements Laboratory at Physics department, Qena faculty of science, south valley university, $\operatorname{Egypt}(4)$.

The soil was taken to the laboratory from a collection spot wrapped in plastic bags. The soil may be crushed to reduce the size of stones, sieved to remove sample content above a desired size, blended to obtain a more homogenous distribution of particle sizes, or milled to reduce the particle size of the soil. If the sample was sieved or split in the field or a small sample was taken, the preparation process may be eliminated. For some purposes, it is possible to remove large nonporous stones and not grind them to size, but they must be weighed separately and an appropriate allowance made. As a general rule, each soil sample was individually dried under laboratory temperature and also we used oven at $50{ }^{\circ} \mathrm{C}$ at least 2 days. The dry soil was ground, pulverized, homogenized and sieved to pass through $2 \mathrm{~mm}$ mesh $(5,6)$. The meshed soil samples were transferred to Marinelli beakers (1000 $\mathrm{ml}$ capacity) or a bottle $(1000 \mathrm{ml}$ and $250 \mathrm{ml}$ capacity) for gamma activity analysis. Each soil sample were weighed and carefully sealed for 4 weeks to reach secular equilibrium between ${ }^{226} \mathrm{Ra}$ and its daughters.

\subsection{Detector}

$\mathrm{NaI}$ (Tl) provides the greatest light output of all of the traditional inorganic scintillators using standard photomultipliers, it also has the best energy resolution. In this study the low level background gamma-ray spectrometer consists basically of $3 \times 3$ inch NaI (Tl), S-1212-I model, with a 1024 microcomputer multichannel analyzer, 5510 ORTEC Norland used to estimate the specific activity of samples under study. The applied detector has a peak gamma-ray efficiency of $1.2 \times 10^{-5}$ at $1332 \mathrm{keV}$, energy resolution of $7.5 \%$ at $662 \mathrm{keV}$ and operation bias voltage 800-1000 V dc. The detector was housed inside a massive lead shield to reduce the background radiation

\subsection{Measuring procedure}

Gamma-ray spectrometry $\mathrm{NaI}(\mathrm{Tl})$ is a convenient method for measuring the activity of radioactive nuclei emitting gamma-rays. In laboratory conditions a sample is placed close to the sensitive volume of the detector and the gamma- ray spectrum is measured. In the spectrum all the photons that interact with the material within the sensitive volume of the detector are registered. Since radioactive atoms emit a discrete spectrum of photons, peaks in the spectrum occur at these photon energies due to interactions leading to full absorption of the photon energy within the sensitive volume. Only quantities describing the intensity of peaks in the spectra are the subject of this work.

After the measurement has been competed (18 hours counting time), the peak areas in the spectrum are calculated and corrected for counting losses. The corrected peak areas are proportional to the number of radioactive atoms that have decayed in the sample during the time of the measurement. Neglecting the probability for coincident detection of two or more gamma-rays, the factor of proportionality is given by the product of two probabilities: the probability that during the decay a gamma-ray with energy $\mathrm{E}$ is emitted and the probability that this gamma-ray is registered in the spectrum in the full-energy peak.

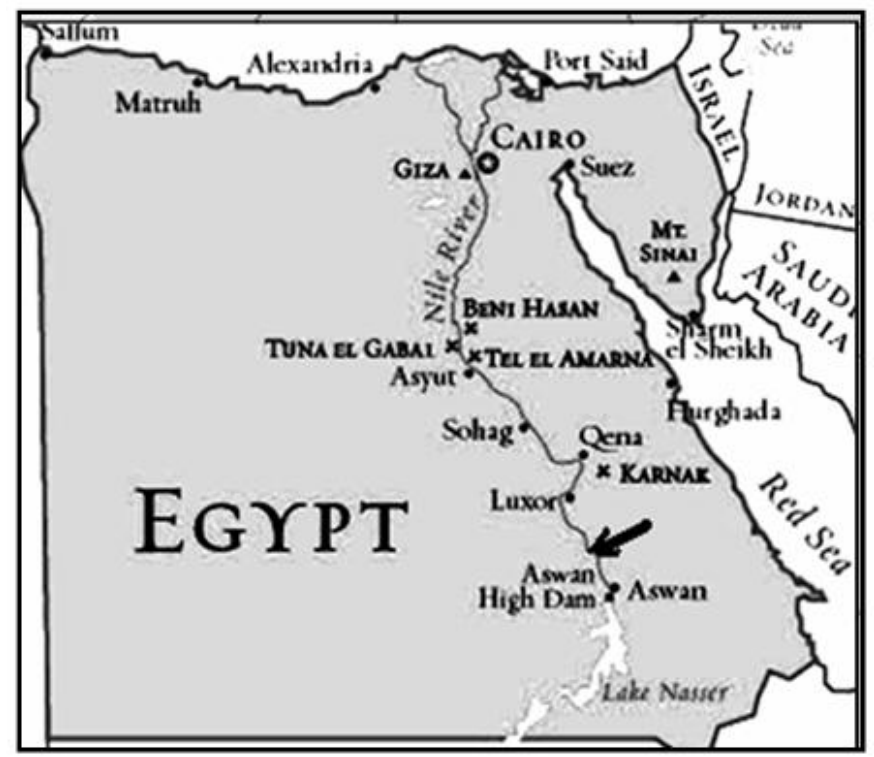

Figure 1. The map of the area under investigation 
Following the spectrum analysis, count rates for each detected photopeak and activity per mass unit (radiological concentration) for each of the detected nuclides are calculated. The specific activity (in Bq kg ${ }^{-1}$ ), $A$ ${ }_{E i}$, of a nuclide $\mathrm{i}$ and for a peak at energy $\mathrm{E}$, is given by (7):

$$
A_{E i}=\frac{N P}{t_{c} \times I_{\gamma}\left(E_{\gamma}\right) \times \varepsilon\left(E_{\gamma}\right) \times M}
$$

where $N P$ is the number of counts in a given peak area corrected for background peaks of a peak at energy $E, \varepsilon_{E}\left(E_{\gamma}\right)$ the detection efficiency at energy $E, t$ is the counting lifetime, $\mathrm{I}_{\square}\left(E_{\gamma}\right)$ the number of gammas per disintegration of this nuclide for a transition at energy $E$, and $M$ the mass in $\mathrm{kg}$ of the measured sample. If there is more than one peak in the energy analysis range for a nuclide, then an attempt to average the peak activities is made. The result is then the weighted average nuclide activity. Based on the measured $\gamma$-ray photopeaks, emitted by specific radionuclides in the ${ }^{232} \mathrm{Th}$ and ${ }^{238} \mathrm{U}$ decay series, their radiological concentrations in samples collected were determined. Calculations relied on establishment of secular equilibrium in the samples, due to the much smaller lifetime of daughter radionuclides in the decay series of ${ }^{232}$ Th and ${ }^{238} \mathrm{U}$.

\section{Internal and external gamma radiation exposure from soil}

The following are potential pathways of exposure to radioactive soil contaminants in a residential setting and are addressed by this guidance document:

- External radiation exposure from radionuclides in soil

- Direct ingestion of soil

- Inhalation of dusts

As usually observed in environmental samples, the concentrations of the radionuclides were better represented by the log-normal distribution, and the central tendency thus is represented by the geometric average. When the number of samples was less than three, the geometric average was determined by considering the similarity with the other results (8).

\subsection{Modeling of transfer of radionuclides from soils to man \\ 1.4.1. External gamma radiation exposure from soil}

One of the principal dose pathways resulting from contaminated surface soil is external exposure from radiation emitted from the radionuclides present in the surface soil. The dose to individuals from external exposure will depend on a number of factors including the type and energy of the emitted radiations. the distribution of the source with depth in the soil, the relative amount of time spent outdoors versus indoors, the amount of shielding provided by on-site structures and the body itself, and even the moisture content of the soil.

The dose from external irradiation is caused by the photons penetrating the human body from gamma emitting radionuclides. Therefore, the relation between dose and radioactivity is more complicated, depending not only on the radioactivity, but also on the geometry in which the radioactivity is distributed, on shielding effects, on self-absorption effects and on the distance to the source. Dose coefficients for external irradiation are expressed in dose rate (i.e. $\mathrm{m} \mathrm{Sv}$ per hour, $\mathrm{m} \mathrm{Sv} \mathrm{h}^{-1}$ ) per activity content of the source (i.e. Bq per kilogram, Bq $\mathrm{kg}^{-1}$ ). In the present case, suitable dose coefficients are calculated for each nuclide and age group, the dose coefficients are given in tables in (9).

The annual effective dose from external gamma radiation.

$\mathrm{H}_{\text {Ext, } \mathrm{a}}=\mathrm{f}_{\text {Con, a }} \sum\left(\mathrm{H}_{\mathrm{x}, \mathrm{s}}-\mathrm{H}_{\mathrm{x}}\right) \cdot \mathrm{t}_{\text {Exp }, \mathrm{a}, \mathrm{s}} \cdot \mathrm{a}_{\mathrm{x}, \mathrm{s}}$

where:

$\mathrm{H}_{\mathrm{E}, \mathrm{a}} \quad$ annual effective dose from external gamma radiation for reference man in $\mathrm{Sv}$

$\mathrm{H}_{\mathrm{x}, \mathrm{s}} \quad$ Photon - equivalent dose in air at $1 \mathrm{~m}$ above ground in exposure work place in $\mathrm{Sv}$

$\mathrm{H}_{\mathrm{x}}^{\mathrm{U}} \quad$ Photon - equivalent dose for natural gamma radiation in air at a height of $1 \mathrm{~m}$ above ground in $\mathrm{Sv}$ $\mathrm{h}^{-1}$

$\mathrm{f}_{\text {con, a }}$ Conversion factor from photon-equivalent dose to effectivie dose for reference man

$\mathrm{t}_{\text {Exp, a, } \mathrm{s}}$ the annual spent time on the exposure site $\mathrm{s}$ in $\mathrm{h}$ 
$a_{x, s} \quad$ factor for considration of the shield (protection) on the exposure site $\mathrm{s}$ for gamma radiation in air nondimensional.

$$
\begin{aligned}
& \mathrm{H}_{\mathrm{x}, \mathrm{s}}^{\mathrm{V}}=\mathrm{C}_{\text {soil }, \mathrm{s}} \cdot \mathrm{g}_{\text {ext }} \\
& \mathrm{H}_{\mathrm{x}}^{\mathrm{U}}=\mathrm{C}_{\text {Soil }}^{\mathrm{U}} \cdot \mathrm{g}_{\text {ext }}
\end{aligned}
$$

where:

$\mathrm{C}_{\text {soil, s }}$ Specific activity for radionuclide where the Uranium-Radium series in radioactive equilibrium for surface soil layers $(0-30 \mathrm{~cm})$ for the exposure site $\mathrm{s}$ in $\mathrm{Bq} \mathrm{kg}^{-1}$ for dry soil

$\mathrm{C}_{\text {Soil }}^{\mathrm{U}} \quad$ Specific natural subsurface activity for radionuclide where the Uranium-Radium series in radioactive equilibrium for surface soil layers $(0-30 \mathrm{~cm})$ for the exposure site $\mathrm{s}$ in $\mathrm{Bq} \mathrm{kg}^{-1}$ for dry soil

$\mathrm{g}_{\text {ext }}$ Conversion factor for the conversion the Specific activity of soil Uranium-Radium series in radioactive equilibrium)to the photon-equivalent dose in air at a height of $1 \mathrm{~m}$ above ground in $\mathrm{Sv} \mathrm{kg} \mathrm{Bq}^{-1} \mathrm{~h}^{-1}$

$$
\mathrm{g}_{\mathrm{ext}}=5.3 \cdot 10^{-10} \mathrm{~Sv} \mathrm{~kg} \mathrm{~Bq}{ }^{-1} \mathrm{~h}^{-1}
$$

\subsubsection{Internal gamma radiation exposure from inhalation dust}

Another potential pathway for human doses from contaminated sites is inhalation of airborne radionuclides on soil. The potential exposure from this pathway depends on a number of factors including the average activity of the soil, the length of time exposed either inside or outdoors, the particle size distribution of the suspended soil, the nuclide and its chemical form, and the age and breathing rate of the person exposed.

Dose coefficients for inhalation dust are also contained in the (9) with table III-2 applying to 6 age groups of the general population. The dose coefficients relate the individual effective dose (in $\square \mathrm{Sv}$ ) to the ingested quantity of radioactivity (in $\mathrm{Bq} \mathrm{kg}^{-1}$ ).

Annual effective dose from inhalation dust $\mathrm{H}_{\text {Inh, a }}$ is calculated as the following:-

$$
\mathrm{H}_{\text {Inh, a }}=\dot{\mathrm{V}}_{\mathrm{a}} \sum_{\mathrm{s}} \sum_{\mathrm{r}}\left(\mathrm{C}_{\text {air }, \mathrm{r}, \mathrm{s}}-\mathrm{C}_{\mathrm{ait,r}, \mathrm{r}}^{\mathrm{U}}\right) \mathrm{g}_{\text {Inh.r, a }} \cdot \mathrm{t}_{\text {Exp }, \mathrm{a}, \mathrm{s}} \cdot \mathrm{a}_{\text {air, } \mathrm{s}}
$$

where

$\mathrm{H}_{\text {Inh. }} \quad$ annual effective dose from inhalation of dust for reference man a in Sv.

$\mathrm{C}_{\mathrm{air}, \mathrm{r}, \mathrm{s}} \quad$ ctivity concentration of dust for radionuclide $\mathrm{r}$ in external air for for the exposure site $\mathrm{s}$ in $\mathrm{Bq} \mathrm{m}^{-3}$

$\mathrm{C}_{\mathrm{air}, \mathrm{r}}^{\mathrm{U}}$

natural subsoil-activity concentration of the dust for radionuclide $r$ in external air for the exposure site $\mathrm{s}$ in $\mathrm{Bq} \mathrm{m}^{-3}$

$$
\mathrm{C}_{\mathrm{air}, \mathrm{r}}^{\mathrm{U}}=0
$$

$\mathrm{V}_{\mathrm{a}} \quad$ breath rate for reference man a in $\mathrm{m}^{3} \mathrm{~h}^{-1}$

$\mathrm{g}_{\mathrm{Inh}, \mathrm{r}, \mathrm{a}} \quad$ coefficient of inhalation dose for radionuclide rand reference man a in $\mathrm{Sv} \mathrm{Bq}^{-1}$

$\mathrm{t}_{\text {Exp, a, } \mathrm{s}} \quad$ the annual time spent on the exposure site $\mathrm{s}$ in $\mathrm{h}$

$\mathrm{a}_{\text {air, }} \mathrm{s} \quad$ factor to determine the concentration of dust on exposure site s from concentration of dust in are, non dimensional ( $\mathrm{a}_{\text {air, }}=1$ for spent in outdoor and $\mathrm{a}_{\text {air }, \mathrm{s}}=0.5$ for spent in indoor) in the investigation, the radiation exposure for the following radionuclides: $\quad\left({ }^{238} \mathrm{U},{ }^{234} \mathrm{U},{ }^{230} \mathrm{Th}\right.$, ${ }^{226} \mathrm{Ra},{ }^{210} \mathrm{~Pb},{ }^{210} \mathrm{Po},{ }^{235} \mathrm{U},{ }^{231} \mathrm{~Pa}$ and $\left.{ }^{227} \mathrm{Ac}\right)$

$\mathrm{C}_{\mathrm{air}, \mathrm{r}, \mathrm{s}}=\left(\mathrm{C}_{\mathrm{soil}(0.02), \mathrm{r}, \mathrm{s}}-C_{\text {soil }(0.02), r}^{U}\right) \mathrm{S}_{\mathrm{dust}}$

$\mathrm{C}_{\text {soil (0.02), r, s }}$ Specific activity of radionuclids $\mathrm{r}$ in the fraction of dust $(<0.02 \mathrm{~mm})$ which the surface soil layers for exposure site in $\mathrm{Bq} \mathrm{kg}$ for dry soil.

$\mathrm{C}_{\text {soil }(0,02) \mathrm{r}}^{\mathrm{U}} \quad$ Specific natural subsoil - activity for radionuclids $\mathrm{r}$ in the fraction of dust $(<0.02 \mathrm{~mm})$ which the surface soil layers for exposure site in $\mathrm{Bq} \mathrm{kg}^{-1}$ for dry soil

$S_{\text {dust }} \quad$ Reference value of the concentration of dust $=5.10^{-8} \mathrm{~kg} \mathrm{~m}^{-3}$

$\mathrm{C}_{\text {soil }(0.02), \mathrm{r}, \mathrm{s}}=\left(\mathrm{C}_{\text {soil, } \mathrm{r}, \mathrm{s}}-\mathrm{C}_{\text {soil, } \mathrm{r}}^{\mathrm{U}}\right) \mathrm{AF}_{0.02, \mathrm{r}}$

$\mathrm{C}_{\text {soil, }, \mathrm{s}} \quad$ Specific activity of radionuclides $\mathrm{r}$ in all samples which the surface soil layers for exposure site in $\mathrm{Bq} \mathrm{kg}{ }^{-1}$ for dry soil 
$\mathrm{C}_{\text {soil, r }}^{\mathrm{U}}$

Specific natural subsoil-activity for radionuclides in all samples which the surface soil layers in

$\mathrm{Bq} \mathrm{kg}^{-1}$ for dry soil

$\mathrm{AF}_{0.02, \mathrm{r}} \approx 4$ for all radionuclide $\mathrm{r}$

\subsubsection{Internal gamma radiation exposure from ingestion direct soil.}

Dose coefficients for ingestion are contained in the (9). The dose coefficients in Tables of [BfS99], apply for 6 age groups of the general population. The dose coefficients relate the individual effective dose (in Sv) to the ingested quantity of radioactivity (in $\mathrm{Bq} \mathrm{kg}^{-1}$ ).

Annual effective dose $\mathrm{H}_{\text {ing,soil,a }}$ for reference man from direct ingestion soil

$\mathrm{H}_{\text {Ing,soil, a }}=\mathrm{U}_{\text {soil, a }} \sum_{s} \mathrm{t}_{\text {Exp,a,s }} \sum_{\mathrm{r}}\left(\mathrm{C}_{\text {soil }(0,5) \mathrm{r}, \mathrm{s}}-\mathrm{C}_{\text {soil }(0,5) \mathrm{r}}^{\mathrm{U}}\right) \mathrm{g}_{\text {Ing, r, a }}$

Where:

$\mathrm{H}_{\text {Ing, soil, a }} \quad$ annual effective dose from direct ingestion of soil for reference man per year in $\mathrm{Sv}$

$\mathrm{C}_{\text {soil (0.5), } \mathrm{r}, \mathrm{s}} \quad$ Specific activity of radionuclides $\mathrm{r}$ in fine particles $(<0.5 \mathrm{~mm})$ which the surface soil layers for exposure site in $\mathrm{Bq} \mathrm{kg}^{-1}$ for dry soil.

$\mathrm{C}_{\text {soil(0,5),r }}^{\mathrm{u}} \quad$ Specific natural subsoil-activity for radionuclides $\mathrm{r}$ in fine particles $(<0.5 \mathrm{~mm})$ which the surface soil layers for exposure site in $\mathrm{Bq} \mathrm{kg}^{-1}$ for dry soil.

$\mathrm{U}_{\text {soil, a }} \quad$ Taking rate of soil for reference man a in $\mathrm{kg} \mathrm{h}^{-1}$ exposure site in $\mathrm{h}$

$t_{E x p, a, s} \quad$ annual spent time on the exposure site $s$ in $h$

$\mathrm{g}_{\text {Ing, } \mathrm{r}, \mathrm{a}} \quad$ Coefficient of ingestion dose for the radionuclide $\mathrm{r}$ and reference man a in Sv Bq in the investigation. the radiation exposure for the following radionuclides:

$\left({ }^{238} \mathrm{U},{ }^{234} \mathrm{U},{ }^{230} \mathrm{Th},{ }^{226} \mathrm{Ra},{ }^{210} \mathrm{~Pb},{ }^{210} \mathrm{Po},{ }^{235} \mathrm{U},{ }^{231} \mathrm{~Pa}\right.$ and $\left.{ }^{227} \mathrm{Ac}\right)$

$\mathrm{C}_{\text {soil (0.05),r,s }}=\left(\mathrm{C}_{\text {soil.r.s }}-\mathrm{C}_{\text {soil } \mathrm{r}}^{\mathrm{U}}\right) \mathrm{AF}_{0.02, \mathrm{r}}$

$\mathrm{C}_{\text {soil, } \mathrm{r}, \mathrm{s}} \quad$ Specific activity of radionuclides $\mathrm{r}$ in all samples which the surface soil layers for exposure site in $\mathrm{Bq} \mathrm{kg}^{-1}$ for dry soil

$\mathrm{C}_{\text {soil } \mathrm{U}}^{\mathrm{U}} \quad$ Specific natural subsoil-activity for radionuclides in all samples which the surface soil layers in

$\mathrm{Bq} \mathrm{kg}^{-1}$ for dry soil

$\mathrm{AF}_{0.05, \mathrm{r}} \approx 2$ for all radionuclide $\mathrm{r}$

\section{Results}

Table 1 The Minimum and maximum of activity concentration for ${ }^{226} \mathrm{Ra}$ and ${ }^{228} \mathrm{Ra}$ in different type of soil samples (cultivated, uncultivated and phosphate)

\begin{tabular}{|l|l|l|l|}
\hline Type of soil & statistics & ${ }^{226} \mathrm{Ra}$ & ${ }^{228} \mathrm{Ra}$ \\
\hline \multirow{2}{*}{ cultivated } & Min & $13.2 \pm 0.5$ & $12.2 \pm 0.5$ \\
\cline { 2 - 4 } & Max & $34.3 \pm 1.3$ & $24.4 \pm 0.9$ \\
\hline \multirow{2}{*}{ uncultivated } & Min & $5.5 \pm 0.3$ & $4.0 \pm 0.2$ \\
\cline { 2 - 4 } & Max & $41.8 \pm 1.5$ & $22.0 \pm 0.8$ \\
\hline \multirow{2}{*}{ phosphate } & Min & $20.7 \pm 0.7$ & $125.1 \pm 42$ \\
\cline { 2 - 4 } & Max & $590.9 \pm 19.2$ & $277.4 \pm 1.5$ \\
\hline
\end{tabular}

In the table 1 The activity concentration ranged for ${ }^{226} \mathrm{Ra}$ was $13.2 \pm 0.5-34.3 \pm 1.3$ and for ${ }^{228} \mathrm{Ra}$ was 12.2 $\pm 0.5-24.4 \pm 0.9$, for ${ }^{226} \mathrm{Ra}$ was $5.5 \pm 0.3-41.8 \pm 1.5$ and for ${ }^{228} \mathrm{Ra}$ was $4.0 \pm 0.2-22.0 \pm 0.8$ and for ${ }^{226} \mathrm{Ra}$ $20.7 \pm 0.7-590.9 \pm 19.2$ and for ${ }^{228} \mathrm{Ra}$ was $125.1 \pm 42-277.4 \pm 1.5$ for cultivated, uncultivated and phosphate soil samples respectively.

Table 2 Annual External gamma radiation Exposure (in $\mathrm{m} \mathrm{Sv}$ ) for ${ }^{226} \mathrm{Ra},{ }^{228} \mathrm{Ra}$ and total of ${ }^{226} \mathrm{Ra}$ and ${ }^{228} \mathrm{Ra}$ from different soils (Cultivated, Uncultivated and Phosphate) with different ages

\begin{tabular}{|l|l|l|l|l|l|l|l|}
\hline Type of soil & Radionuclides & $<1 \mathrm{a}$ & $1-2 \mathrm{a}$ & $2-7 \mathrm{a}$ & $7-12 \mathrm{a}$ & $12-17 \mathrm{a}$ & $>17 \mathrm{a}$ \\
\hline \multirow{5}{*}{ cultivated } & U series (Ra-226) & 0.0148 & 0.0130 & 0.0130 & 0.0130 & 0.0111 & 0.0111 \\
\cline { 2 - 8 } & Th series (Ra-228) & 0.0150 & 0.0132 & 0.0132 & 0.0132 & 0.0113 & 0.0113 \\
\cline { 2 - 8 } & Total & 0.0299 & 0.0261 & 0.0261 & 0.0261 & 0.0224 & 0.0224 \\
\hline \multirow{5}{*}{ uncultivated } & U series (Ra-226) & 0.0179 & 0.0157 & 0.0157 & 0.0157 & 0.0135 & 0.0135 \\
\cline { 2 - 8 } & Th series (Ra-228) & 0.0207 & 0.0181 & 0.0181 & 0.0181 & 0.0155 & 0.0155 \\
\cline { 2 - 8 } & Total & 0.0386 & 0.0338 & 0.0338 & 0.0338 & 0.0290 & 0.0338 \\
\hline \multirow{5}{*}{ phosphate } & U series (Ra-226) & 0.3755 & 0.3286 & 0.3286 & 0.3286 & 0.2816 & 0.2816 \\
\cline { 2 - 8 } & Th series (Ra-228) & 0.0476 & 0.0417 & 0.0417 & 0.0417 & 0.0357 & 0.0357 \\
\cline { 2 - 8 } & Total & 0.4231 & 0.3702 & 0.3702 & 0.3702 & 0.3173 & 0.3173 \\
\hline
\end{tabular}


In the table 2, The calculated annual effective dose of external exposure for the ${ }^{226} \mathrm{Ra}\left(\mathrm{U}\right.$-series) ${ }^{228} \mathrm{Ra}$ (Th-series) and its total radionuclides in Cultivated soil, were obtained as $0.0148 \mathrm{~m} \mathrm{~Sv}$, for infants $(<1 \mathrm{a})$, $0.0130 \mathrm{~m} \mathrm{~Sv}$ for children $(2-7 \mathrm{a})$ and $0.0111 \mathrm{~m} \mathrm{~Sv}$ for adults $(>17 \mathrm{a})$ and $0.0150 \mathrm{~m} \mathrm{~Sv}$, for infants $(<1 \mathrm{a}), 0.0132$ $\mathrm{m} \mathrm{Sv}$ for children $(2-7 \mathrm{a}), 0.0113 \mathrm{~m} \mathrm{~Sv}$ for adults $(>17 \mathrm{a})$ and the total external exposure are $0.0299 \mathrm{~m} \mathrm{~Sv}$, for infants (<1 a), $0.0261 \mathrm{~m} \mathrm{~Sv}$ for children $(2-7 \mathrm{a}), 0.0224 \mathrm{~m} \mathrm{~Sv}$ for adults (>17 a) for ${ }^{226} \mathrm{Ra}$ (U-series) ${ }^{228} \mathrm{Ra}(\mathrm{Th}-$ series) and its total radionuclides respectively.

The calculated annual effective dose of external exposure for the ${ }^{226} \mathrm{Ra}$ (U-series) ${ }^{228} \mathrm{Ra}$ (Th-series) and its total radionuclides in Uncultivated soil, were obtained as $0.0179 \mathrm{~m} \mathrm{~Sv}$, for infants (<1 a), $0.0157 \mathrm{~m} \mathrm{~Sv}$ for children $(2-7 \mathrm{a})$ and $0.0135 \mathrm{~m} \mathrm{~Sv}$ for adults $(>17 \mathrm{a})$ and $0.0207 \mathrm{~m} \mathrm{~Sv}$, for infants $(<1 \mathrm{a}), 0.0181 \mathrm{~m} \mathrm{~Sv}$ for children (2-7 a), $0.0155 \mathrm{~m} \mathrm{~Sv}$ for adults $(>17 \mathrm{a})$ and the total external exposure are $0.0386 \mathrm{~m} \mathrm{~Sv}$, for infants $(<1$ a), $0.0338 \mathrm{~m} \mathrm{~Sv}$ for children $(2-7 \mathrm{a}), 0.0338 \mathrm{~m} \mathrm{~Sv}$ for adults (>17 a) for ${ }^{226} \mathrm{Ra}$ (U-series) ${ }^{228} \mathrm{Ra}$ (Th-series) and its total radionuclides respectively.

The calculated annual effective dose of external exposure for the ${ }^{226} \mathrm{Ra}$ (U-series) ${ }^{228} \mathrm{Ra}$ (Th-series) and its total radionuclides in Phosphate soil, were obtained as $0.3755 \mathrm{~m} \mathrm{~Sv}$, for infants $(<1 \mathrm{a}), 0.3286 \mathrm{~m} \mathrm{~Sv}$ for children $(2-7 \mathrm{a})$ and $0.2816 \mathrm{~m} \mathrm{~Sv}$ for adults $(>17 \mathrm{a})$ and $0.0476 \mathrm{~m} \mathrm{~Sv}$, for infants $(<1 \mathrm{a}), 0.0417 \mathrm{~m} \mathrm{~Sv}$ for children (2-7 a), $0.0357 \mathrm{~m} \mathrm{~Sv}$ for adults $(>17 \mathrm{a})$ and the total external exposure are $0.4231 \mathrm{~m} \mathrm{~Sv}$, for infants $(<1$ a), $0.3702 \mathrm{~m} \mathrm{~Sv}$ for children (2-7 a), $0.3173 \mathrm{~m} \mathrm{~Sv}$ for adults (>17 a) for ${ }^{226} \mathrm{Ra}$ (U-series) ${ }^{228} \mathrm{Ra}$ (Th-series) and its total radionuclides respectively.

In fig. $2 \mathrm{~A}$ and table 2 we can see that the annual external dose rate for ${ }^{226} \mathrm{Ra}$ (U-series) ${ }^{228} \mathrm{Ra}(\mathrm{Th}-$ series) are nearly the same vales of annual external gamma radiation exposure ( $\mathrm{m} \mathrm{Sv}$ ) for group age but in the fig. $2 \mathrm{C}$ the value of annual external gamma radiation exposure for $226 \mathrm{Ra}$ (U-series) is more than for ${ }^{228} \mathrm{Ra}$ (Th-series).

A

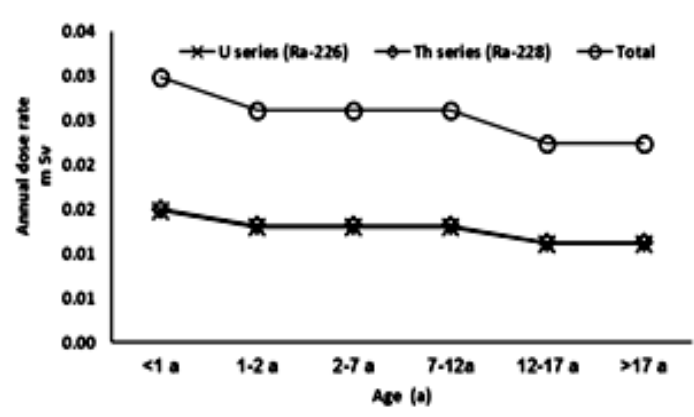

C

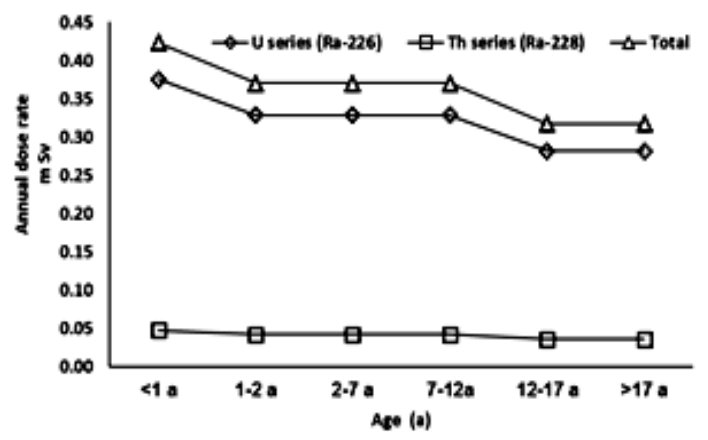

B

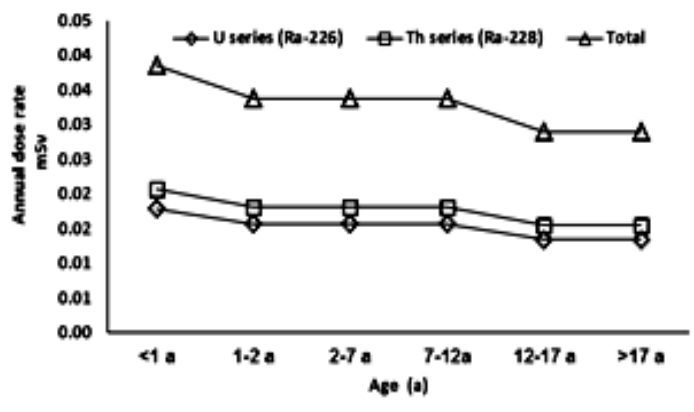

Figure 2. Annual External gamma radiation Exposure for ${ }^{226} \mathrm{Ra},{ }^{228} \mathrm{Ra}$ and total of ${ }^{226} \mathrm{Ra}$ and ${ }^{228} \mathrm{Ra}$ from different soils A) Cultivated $\quad$ B) Uncultivated $\quad$ C) Phosphate with different ages.

Fig. 3 and Table 3, showing the relationship between the group age and annual dose equivalents from gamma radiation from U-series and Th-series, enable exposures to be estimated in outdoor from inhalation soil of various specific activities.

The highest total inhalation exposure was $0.9736 \mu \mathrm{Sv}^{-1}$ for age $>17$ a old compared to another total inhalation exposure for different ages and also the total inhalation exposure from phosphate soil more higher than from the Cultivated, Uncultivated soil. 
Estimation of annual external exposure and internal exposure dose rate for gamma ray from the ..

Table 3 Annual inhalation gamma radiation Exposure (in $\mu \mathrm{Sv} \mathrm{a}^{-1}$ ) for ${ }^{226} \mathrm{Ra},{ }^{228} \mathrm{Ra}$ and total of ${ }^{226} \mathrm{Ra}$ and ${ }^{228} \mathrm{Ra}$ from different soils (Cultivated, Uncultivated and Phosphate) with different ages.

\begin{tabular}{|l|l|l|l|l|l|l|l|}
\hline Type of soil & Radionuclides & $<1 \mathrm{a}$ & $1-2 \mathrm{a}$ & $2-7 \mathrm{a}$ & $7-12 \mathrm{a}$ & $12-17 \mathrm{a}$ & $>17 \mathrm{a}$ \\
\hline cultivated & U series (Ra-226) & 0.0125 & 0.0169 & 0.0176 & 0.0219 & 0.0264 & 0.0227 \\
\cline { 2 - 8 } & Th series (Ra-228) & 0.0351 & 0.0595 & 0.0721 & 0.0901 & 0.1137 & 0.1258 \\
\cline { 2 - 8 } & Total & 0.0476 & 0.0764 & 0.0897 & 0.1119 & 0.1400 & 0.1485 \\
\hline uncultivated & U series (Ra-226) & 0.0152 & 0.0204 & 0.0213 & 0.0265 & 0.0319 & 0.0275 \\
\cline { 2 - 8 } & Th series (Ra-228) & 0.0483 & 0.0819 & 0.0992 & 0.1239 & 0.1564 & 0.1731 \\
\cline { 2 - 8 } & Total & 0.0634 & 0.1023 & 0.1205 & 0.1504 & 0.1883 & 0.2006 \\
\hline phosphate & U series (Ra-226) & 0.3180 & 0.4276 & 0.4453 & 0.5541 & 0.6679 & 0.5751 \\
\cline { 2 - 8 } & Th series (Ra-228) & 0.1110 & 0.1885 & 0.2283 & 0.2852 & 0.3599 & 0.3984 \\
\cline { 2 - 8 } & Total & 0.4291 & 0.6161 & 0.6735 & 0.8393 & 1.0278 & 0.9736 \\
\hline
\end{tabular}

A

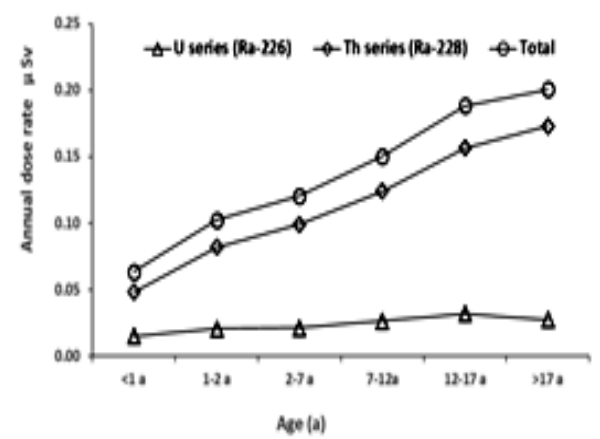

C

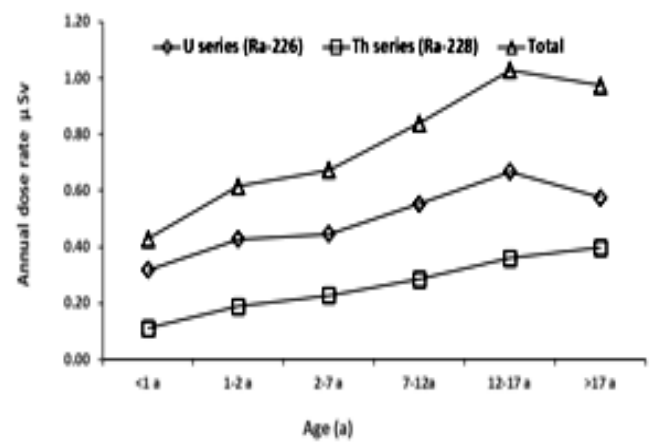

B

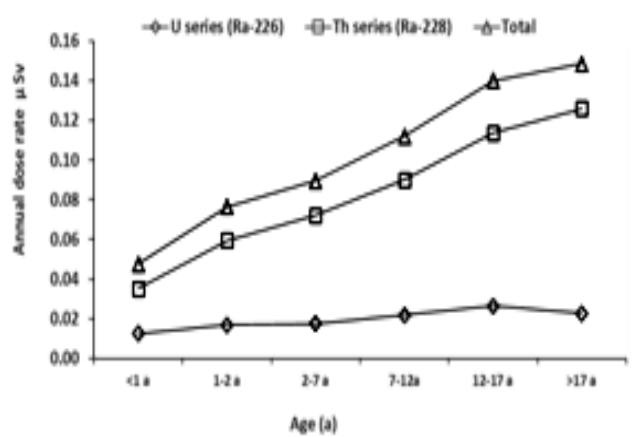

Figure 3 Annual Inhalation gamma radiation Exposure for ${ }^{226} \mathrm{Ra},{ }^{228} \mathrm{Ra}$ and total of ${ }^{226} \mathrm{Ra}$ and ${ }^{228} \mathrm{Ra}$ from $\begin{array}{llll}\text { different soils A) Cultivated } & \text { B) Uncultivated } & \text { C) Phosphate with different ages }\end{array}$

Table 4 Annual ingestion gamma radiation Exposure for ${ }^{226} \mathrm{Ra},{ }^{228} \mathrm{Ra}$ and total of ${ }^{226} \mathrm{Ra}$ and ${ }^{228} \mathrm{Ra}$ from different soils (Cultivated, Uncultivated and Phosphate) with different ages

\begin{tabular}{|l|l|l|l|l|l|l|l|}
\hline Type of soil & Radionuclides & $<1 \mathrm{a}$ & $1-2 \mathrm{a}$ & $2-7 \mathrm{a}$ & $7-12 \mathrm{a}$ & $12-17 \mathrm{a}$ & $>17 \mathrm{a}$ \\
\hline \multirow{4}{*}{ cultivated } & U series (Ra-226) & 0.000 & 3.346 & 1.296 & 0.334 & 0.627 & 0.117 \\
\cline { 2 - 8 } & Th series (Ra-228) & 0.000 & 1.217 & 0.568 & 0.094 & 0.081 & 0.074 \\
\cline { 2 - 8 } & Total & 0.000 & 4.564 & 1.865 & 0.428 & 0.708 & 0.191 \\
\hline \multirow{4}{*}{ uncultivated } & U series (Ra-226) & 0.000 & 4.052 & 1.570 & 0.405 & 0.760 & 0.142 \\
\cline { 2 - 8 } & Th series (Ra-228) & 0.000 & 1.676 & 0.782 & 0.130 & 0.112 & 0.103 \\
\cline { 2 - 8 } & Total & 0.000 & 5.727 & 2.352 & 0.535 & 0.871 & 0.245 \\
\hline & U series (Ra-226) & 0.000 & 84.81 & 32.86 & 8.481 & 15.90 & 2.968 \\
\cline { 2 - 8 } & Th series (Ra-228) & 0.000 & 3.856 & 1.799 & 0.298 & 0.257 & 0.236 \\
\cline { 2 - 8 } & Total & 0.000 & 88.66 & 34.66 & 8.779 & 16.15 & 3.205 \\
\hline
\end{tabular}



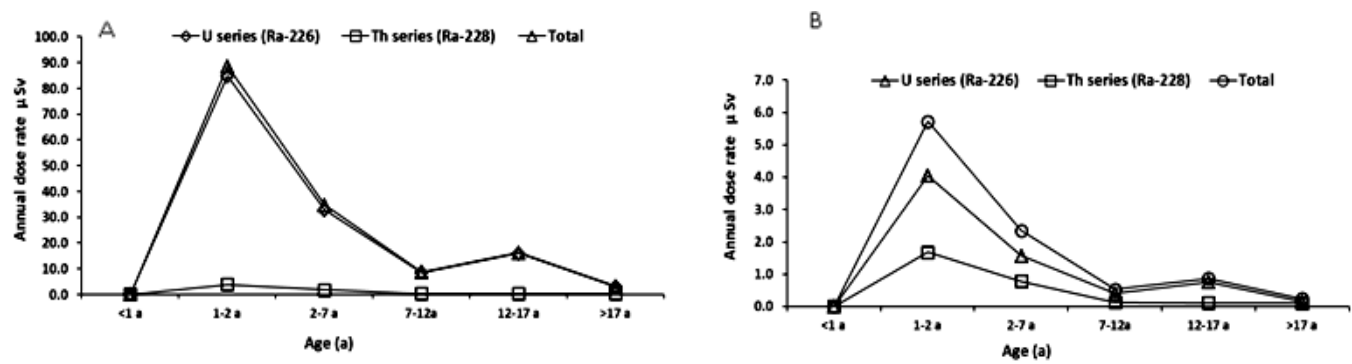

C

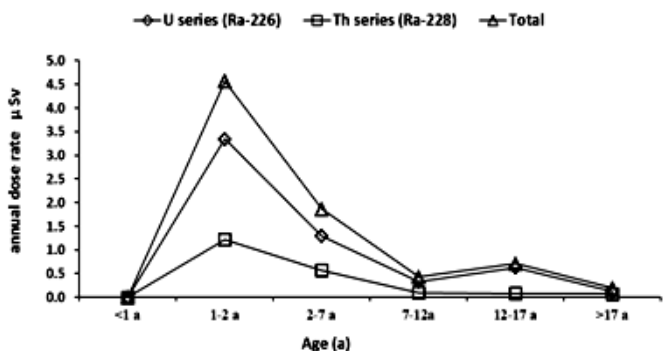

Figure 4 Annual Ingestion gamma radiation Exposure for ${ }^{226} \mathrm{Ra},{ }^{228} \mathrm{Ra}$ and total of ${ }^{226} \mathrm{Ra}$ and ${ }^{228} \mathrm{Ra}$ from different soils A) Cultivated

B) Uncultivated

C) Phosphate with different ages.

Tables 4 list the internal exposure from direct ingestion of radionuclides in soil (dust) from Cultivated, Uncultivated and Phosphate, respectively, with different ages. The highest annual exposure for 1-2 year old for all radionuclides and for all different locations and from the Fig.4 we can see that the same behaviour for internal exposure from direct ingestion of radionuclides in soil for all radionuclides and ages. Table 4 shows the annual direct ingestion of radionuclides in soil in $\mu$ Sv. Also shown are the annual internal exposures due to direct ingestion of dust as a function of age groups. We can see that annual exposure ingestion for baby less than 1 year is zero, and the maximum annual exposure direct ingestion for age 1-2 year for all radionuclides see Fig. 4.

For the Cultivated soil the annual direct ingestion annual exposure are 3.346 for ${ }^{226} \mathrm{Ra} .1 .217$ for ${ }^{228} \mathrm{Ra}$ and 4.564 for its total only for 1-2 year old and for greater than 17 year old are $0.117,0.074$ and 0.191 for ${ }^{226} \mathrm{Ra}$, ${ }^{228} \mathrm{Ra}$ and its total, respectively.

For the Uncultivated soil the annual direct ingestion annual exposure are 4.052 for ${ }^{226} \mathrm{Ra}$. 1.676 for ${ }^{228} \mathrm{Ra}$ and 5.727 for its total only for $1-2$ year old and for greater than 17 year old are $0.142,0.103$ and 0.245 for ${ }^{226} \mathrm{Ra},{ }^{228} \mathrm{Ra}$ and its total, respectively.

For phosphate the annual direct ingestion annual exposure are 84.81 for ${ }^{226} \mathrm{Ra} .3 .856$ for ${ }^{228} \mathrm{Ra}$ and 88.66 for its total only for 1-2 year old and for greater than 17 year old are 2.968, 0.236 and 3.205 for ${ }^{226} \mathrm{Ra}$, ${ }^{228} \mathrm{Ra}$ and its total, respectively.

Table 5 comparison between Annual External, Inhalation and Ingestion Exposure with different type of soil (cultivated Uncultivated and phosphate) and different ages

\begin{tabular}{|l|l|l|l|l|l|l|l|}
\hline Table Exposure & type of soil & $<1 \mathrm{a}$ & $1-2 \mathrm{a}$ & $2-7 \mathrm{a}$ & $7-12 \mathrm{a}$ & $12-17 \mathrm{a}$ & $>17 \mathrm{a}$ \\
\hline \multirow{3}{*}{$\begin{array}{l}\text { Annual } \\
\text { External Exposure }\end{array}$} & cultivated & 0.0299 & 0.0261 & 0.0261 & 0.0261 & 0.0224 & 0.0224 \\
\cline { 2 - 9 } & uncultivated & 0.0386 & 0.0338 & 0.0338 & 0.0338 & 0.0290 & 0.0290 \\
\cline { 2 - 9 } & phosphate & 0.4231 & 0.3702 & 0.3702 & 0.3702 & 0.3173 & 0.3173 \\
\hline \multirow{3}{*}{$\begin{array}{l}\text { Ennual Inhalation } \\
\text { Exposure }\end{array}$} & cultivated & 0.0476 & 0.0764 & 0.0897 & 0.1119 & 0.1400 & 0.1485 \\
\cline { 2 - 9 } & uncultivated & 0.0634 & 0.1023 & 0.1205 & 0.1504 & 0.1883 & 0.2006 \\
\cline { 2 - 9 } & phosphate & 0.4291 & 0.6161 & 0.6735 & 0.8393 & 1.0278 & 0.9736 \\
\hline \multirow{2}{*}{$\begin{array}{l}\text { Annual Ingestion } \\
\text { Exposure }\end{array}$} & cultivated & 0.0000 & 4.5643 & 1.8651 & 0.4288 & 0.7087 & 0.1918 \\
\cline { 2 - 9 } & uncultivated & 0.0000 & 5.7271 & 2.3519 & 0.5347 & 0.8714 & 0.2446 \\
\cline { 2 - 9 } & phosphate & 0.0000 & 88.6669 & 34.6637 & 8.7793 & 16.1591 & 3.2049 \\
\hline
\end{tabular}

In Fig. 5 -A the annual external gamma radiation exposure (m Sv) in shown for three different type of soil , Cultivated, Uncultivated and Phosphate. It is clear from Fig. 5-A that the total (U-series and Th-series) annual external gamma radiation exposure calculate for three different type of soil is the highest value for phosphate, and for Cultivated, and Uncultivated are nearly the same vales of annual external gamma radiation exposure $(\mathrm{m} \mathrm{Sv})$ for group age. 
In Figs. 5-B the total annual internal gamma radiation exposure $(\mu \mathrm{Sv})$ from inhalation in shown for three different type of soil, Cultivated, Uncultivated and Phosphate. It is clear from Fig.5-B that the total (Useries and Th-series) annual external gamma radiation exposure calculate for three different type of soil is the highest value phosphate, and for Cultivated, and Uncultivated are nearly the same vales of annual internal gamma radiation exposure $(\mu \mathrm{Sv})$ from inhalation for group age.

In Fig. 5-C the total internal gamma radiation exposure ( $\mu \mathrm{Sv}$ ) from direct ingestion of soil (dust) in shown for three different type of soil, Cultivated, Uncultivated and Phosphate. It is clear from Fig.5-C that the total (U-series and Th-series) annual internal gamma radiation exposure $(\mu \mathrm{Sv})$ from direct ingestion of soil calculate for three different type of soil is the highest value for phosphate, and for Cultivated, and Uncultivated are nearly the same vales of internal gamma radiation exposure $(\mu \mathrm{Sv})$ from direct ingestion of soil for group age.

A

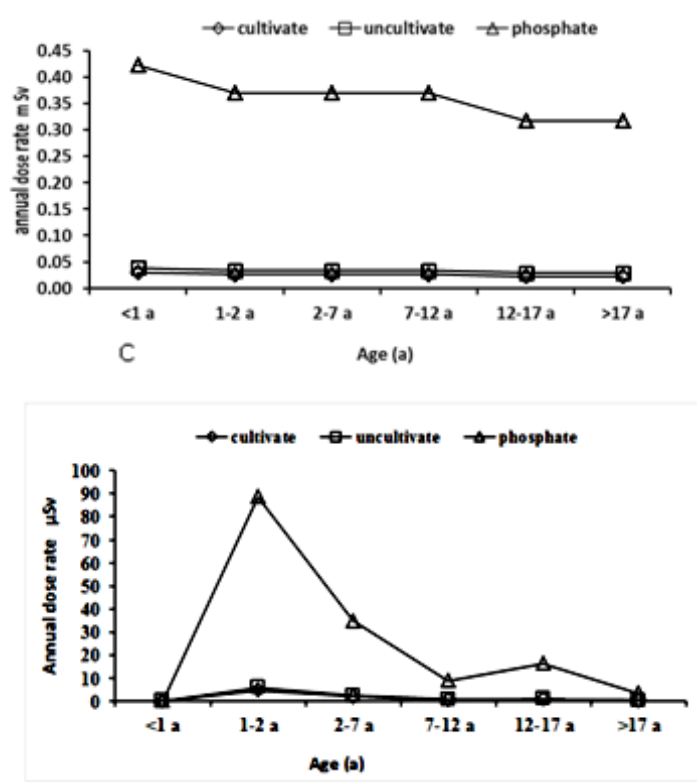

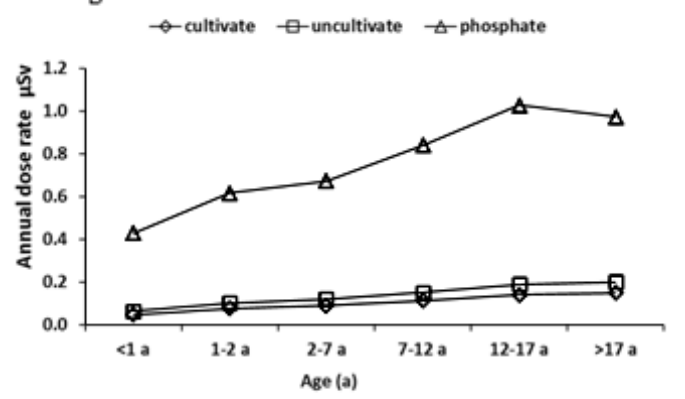

Figure 5 Relation between the different type of soil (cultivated Uncultivated and phosphate) and different ages A) Annual External Exposure, b) Inhalation Exposure and c) Ingestion Exposure

\section{References}

[1]. S. Harb, Natural radioactivity and external gamma radiation exposure at the coastal red sea Egypt, Radiat. Prot. Dos. (2008), 130, 3, 376-384.

[2]. S. Harb, PhD Thesis Z S R. Radiation protection and radioecology, Hannover University, Germany,2004. http://www.zsr.unihannover.de/arbeiten /drharb.pdf.

[3]. B. E. Sample, M. S. Aplin, R. A. Efroymson, G. W Suter. and C. J. E Welsh. "Methods and tools for estimation of the exposure of terrestrial wildlife to contaminants" ORNL/TM-13391 environmental sciences division, publication(1997). No. 4650.

[4]. Mahmoud Hashim Mahmoud, Environmental Impacts of Non Nuclear Industries in Upper-Egypt, Msc, thesis, 2011, Physics Department, Faculty of science, South Valley university

[5]. National council on Radiation Protection and Measurements "Environmental radiation measurements" NCRP Report No. 50, (1976).

[6]. A. Chieco, The procedures manual of the environmental measurements laboratory, HASL-300 volume I, 28 th Edition February, U.S. Department of Energy New York, (1997).

[7]. S. Harb, N. K. Ahmed, Sahar Elnobi, Radon exhalation rate and Radionuclides in soil, phosphate, and building materials, IOSR Journal of Applied Physics, 7, 2 (2015), 41-50.

[8]. E. E. Santos, D. C. Lauria, E. C. S. Amaral, E. R. Rochedo "Daily ingestion of ${ }^{232} \mathrm{Th},{ }^{238} \mathrm{U},{ }^{226} \mathrm{Ra},{ }^{228} \mathrm{Ra}$ and ${ }^{210} \mathrm{~Pb}$ in vegetables by inhabitants of Rio de Janeiro City “ Journal of Environmental Radioactivity, 62 75-86, (2002).

[9]. Bundesamt für Strahlenschutz (BfS)Berechnungsgrundlagen zur Ermittlung der Strahlenexposition infolge bergbaulicher Umweltradioaktivität (Berechnungsgrun-dlage Bergbau), (Stand 30.07.1999). 